\title{
The conceptual design of oil-and-gas metaphorical terms
}

\author{
Zaineta Khachmafova ${ }^{1}$, Tatiana Ostrovskaya ${ }^{1}$, and Elena Skhalyakho ${ }^{1,{ }^{*}}$ \\ ${ }^{1}$ Adyghe State University, Pervomayskaya St., 208, Maykop, Adyghe Republic, 385000, Russia
}

\begin{abstract}
The article presents the stages and problems of conceptual design of metaphorical oil and gas terminology, which is rapidly developing in recent decades, so the purpose of the article is to define the principles of conceptual design of metaphorical terminology and to present some empirical evidence for this. The methodological basis of the article consists of methods that are widely used in linguistics: definitive and cognitive analysis, observation and description of linguistic facts. When considering the structural and semantic characteristics of metaphorical terms, the modeling method and the etymological method were used. The article presents and explains: 1) the main areas of cognitive sources of metaphorical terms in the oil and gas sector and the conceptual structures of metaphorical terminology developed from sources such as human, animal, spatial, medical, coloristic and other areas, which have shown different effectiveness in comparison; 2) Evaluation types, such as Effective Evaluation, Cognitive Evaluation, and Subliminal Evaluation to identify examples of oil and gas terms under study.
\end{abstract}

\section{Introduction}

The need for unambiguous and precise determination of new objects of the scientific and technical component of the world picture requires the production of new terms. One of the sources of new terminological forms: terms, terminoids, and professionalisms is the metaphorization of commonly used words.

It is necessary to focus on the functional and cognitive features of the origin of terminology. The traditional source of terms is the borrowing of Greek-Latin words or the creation of new words based on the models of the Greek-Latin terminology base. Such terms, as a rule, retain their semantics and act as international terms in relation to the national professional language. The basis of the professional dictionary is the words of the national language, which acquire a specific meaning. Terms and terminoids complement and structure the professional language. A special feature of terminoids is their general use and prevalence in the professional sphere, but at the same time the terminoid retains the signs of a commonly used word or neologism. For example, terminoids are characterized by the presence of contextual meaning, nuances of individual interpretation, and absence in the basic terminology dictionary. The transition of a terminoid to a full-fledged term means narrowing and concretizing its meaning, fixing it in professional dictionaries and literature.

\footnotetext{
* Corresponding author: georgy-2583@yandex.ru
} 
The most productive way to replenish the dictionary is to use metaphors (metaphorization) of commonly used words and phrases. The main models of the formation of terms with the help of metaphorization remain: similarity of the form of the called object or phenomenon; similarity of functions; conceptualization of the unity of similarities in form and function; similarity of the internal structure; associative transfer of features.

The human tendency to generalize extra-linguistic reality by linguistic means defines metaphorical transfer as the most productive way to supplement terminology. The principle of saving effort [1] limits the increase in the general linguistic vocabulary by expanding the meanings of existing words, forming doublets, variants, and other forms of polysemy, homonymy.

In this case, the formation of a new terminology faces the opposing forces of purism and internationalism. Puristic views on terminology presuppose the predominant formation of terms from the national language. In this case, the metaphorization of the words of the national language implies the formation of a new narrowly special meaning from the totality of existing ones, for example, the term "site (works)" in the Russian language is formed from the commonly used word "site", that is, from the word "site". limited part of the surface by expanding and specifying the meaning of "limited part of the production process".

The international approach to terminology involves the use of words, including terms, of a foreign language. In addition to the actual borrowing of the term, there may be a metaphorization of the existing international term in the national language. In this case, the meaning of the borrowed term will differ from the original one. It is created by metaphorical transference. A classic example of this phenomenon is the name of the dental instrument "excavator", which is based on the similarity of the functional features of the earthmoving machine and the surgical device.

E. Goatly understands metaphors as unusual language usage potentially capable of expanding the boundaries of familiar categories [1]. Until recently, researchers who held traditional views on language considered metaphor only from a linguistic perspective. They neglected its cognitive component. It has recently been proved that the English language is more metaphorical than it was supposed to be, and metaphor is one of the main ways of conceptualizing the self-given reality and is closely connected with the thought

Every metaphor is a product of the creative cognitive process that is directly influenced by language and depends on the way the reality is conceptualized in culture. Metaphors correlate various objects and phenomena, conceptualize reality according to the principles of analogy, thus helping to understand the self-given reality. The conceptual nature of metaphor and its cognitive aspect became a prerequisite for the study of metaphor within the framework of the cognitive science. Metaphor as a cognitive tool simplifies the process of understanding and cognition. This is due to the ability of the metaphor to concretize and refine concepts by narrowing the meanings. This idea is developed in the works of many scientists who have studied rethinking and recategorization of metaphors: R.Gibbs (2011), M. Turner (2016), Gilles Fauconnier (2011), G. Steen (2011) Z. Kövecses (2020) [2-6]. The linguists focus on the way a metaphor functions, and state that the mechanism of a metaphor is mainly revealed in its usage. While interpreting metaphors the direct meaning of the word should not be discarded since metaphors manifest the coherence of the figurative and direct meanings of the word.

Terminological metaphorization is based on the principles of consistency, selectivity and anthropocentrism. It reflects metaphorical thinking of specialists in a particular field of knowledge and shows the result of the continuous development of scientific thought in technology, economics and industry. Functioning in the professional sphere, metaphor becomes a unique instrument of narrowly focused communication which allows specialists 
to build a conversation. The anthropometricity of a metaphor gives it the ability to serve as a means of creating the linguistic picture of the world.

The communicative orientation of the metaphorical nomination is reflected in the works of R. Trim (2011), who notes that new meanings are created not only to record the results of cognitive and emotional human activity, but also to make these results the property of other people [7].

The process of metaphorization is studied in detail in the works of L. Fan (2018), M. Benedek et al. (2014), R.Bottini, C.F. Doeller (2020), M. Prandi (2012).[8-11]

Our research is based on the theories and methods suggested by G. Lakoff and M. Johnson (2008), V.Novodranova (2011), R.Gibbs (2015), G. Steen(2013) [12-15].

\section{Methodology}

The research material of this article consists of metaphorical terms. Dictionaries, technical reference books, scientific articles, monographs, catalogues, and scientific journals related to the oil and gas industry were used as a source. It should be noted that the terminological vocabulary of the industry is constantly growing due to continuous scientific and technological progress[16-18].

The choice of research methods is determined by the goals and objectives set in the article. The goal statement should answer the following questions:

1. What is metaphorization in terminology?

2. What are the types of assessment to identify the examples of the terms under the study?

3. What are the main cognitive source domains of metaphorical terms in the oil-and-gas sector?

The study is carried out in the nominative-cognitive aspect using the methods of definitional analysis, conceptual integrity-and-cognitive analysis.

\section{Results and Discussion}

\subsection{Terminology and metaphors}

An important role in the formation of a term by metaphorizing an existing word is played by associative models that exist in the collective consciousness.

The associative model at the cognitive level includes the semantic relations of the elements existing in the speaker's mind. The association of many people with professional interests a priori presupposes the existence of uniform elements and the proximity of associative links that form a group perception of the non-linguistic picture of the world from the position of the profession. The basis for the formation of the model is a generic concept that unites elements due to their semantic connections. At the same time, the associative metaphorical model is a natural system of categorization of objects of reality, which encourages speakers to intuitively organize the semantic field. Hence, the linguistic experience of speakers structures metaphorical models, allocating the most productive to the center, and the less productive to the periphery. The discursive nature of associative modeling in the process of metaphorization of the term implies a broad attention to the phenomenon of discourse itself [18-20].

Discourse as an activity mediated by verbal means in the professional sphere imposes significant restrictions on the possibilities of speech abstraction. The possibilities of the language in terms of abstraction have no boundaries. The framework is a person's idea of the limits of a particular phenomenon in the picture of the world, its simplicity or 
complexity, meaning, connections with other elements, etc. In this case, the metaphor acts as a manifestation of the analog capabilities of human thinking. Semantic connections in the metaphorical perception of the world are alien to the formalized inductive or deductive methods of cognition. In fact, the metaphor constructs the world by verbal means, ordering the associative connection

In this case, the metaphor acts as a manifestation of the analog capabilities of human thinking. Semantic connections in the metaphorical perception of the world are alien to the formalized inductive or deductive methods of cognition. In fact, the metaphor constructs the world by verbal means, ordering the associative connection between the existing and the new.

The structure of the metaphorical model of thinking is implemented in the form of interacting aspects: the original conceptual domain - a new conceptual domain-a typical implementation scenario for this model. As such, the metaphorical model acts as a set of formal procedures between two frames. Hence, metaphorical models are characterized by productivity, frequency, and pragmatic potential.

Metaphorization in terminology is a verbal representation of pragmatically reinterpreted scientific knowledge, a reflection of the mentality, professional experience and linguistic and cultural competence of specialists.

The study of terminological metaphorization through actualized features and axiological assessments of lexical units drawn from source domains for the formation of metaphorical terms is a new approach to study the mechanisms of formation of metaphorical nomination in industry terminology. Metaphor is considered to be a way to think about one area through the prism of another. That is, to represent one area of reality (target domain) by transferring representations from an already known area of reality (source domain) to it.

Metaphorical nomination is more often applied to those concepts that are fundamental and have the greatest practical significance for a particular industry.

The modern approach to understanding the role of metaphor in the nomination process considers metaphor as a cognitive mechanism that allows us to comprehend abstract concepts in more precise terms. Therefore, metaphor is one of the fundamental ways of cognition and conceptualization of the self-given reality. J. Lakoff believes that metaphor is the main mechanism by which not only abstract concepts are realized, but also the possibility of abstract thinking is created [12]. And then he concludes that abstract concepts are not complete without metaphors.

The study of metaphorical terms in the terminology of the American oil-and-gas industry indicates the essential importance of metaphorization as a way of term forming. The lexical database for the construction of new metaphors is borrowed from areas that have a common significance and popularity. By referring to certain source domains, some evaluation effect can be caused since the replacement of direct names with expressive ones gives them a different flavor, and is able to emphasize the most significant features of the metaphorized concepts.

\subsection{Types of assessment}

When analyzing the inventory of axiological assessments of actualized features of words and phrases drawn from various source domains to form new metaphorical terms within the terminology of the American oil-and-gas industry we used the classification of the types of assessments which were identified and based on the analysis of examples of the terms under study.

Effective Evaluation is often expressed by metaphors that include semes of emotionality, the vocabulary of name-calling and caressing, sometimes even abusive vocabulary, visual assessments and sensory assessments. 
The source domain "The world of human beings" is characterized by a predominance of acoustic and tactile assessments. E.g.:

a roustabout - flunckey;

screaming monkey-derrickman;

yo-yo - cable-tool driller; spudder.

The above given metaphors nominate unqualified occupations connected with loud cries in the process of fulfilling duties.

to belch - to burp, to puke;

crybaby-ungreased bolt;

weeping core- intermittent flowing operation.

The metaphors nominate unpleasant sounds produced by some equipment.

We consider lexical units that carry a qualitative characteristic of objects, subjects, processes or phenomena to have a pronounced emotional connotation showing some deficiency of an object. E.g.:

baby compressor mobile - low power compressor;

baby driller-inexperienced driller;

baby tower-small-sized evaporation column.

Cognitive Evaluation. In this type of evaluation the use of lexical units for metaphorical term formation acquires an apparent cognitive-pragmatic orientation, i.e. conceptual metaphors.

weather window - a spell of fine weather;

educated guessers- engineers (1);

educated stick-sliding scale (2).

Here, the impressive productivity of the word educated is due to the selection of different characters for the designation of concepts from clearly expressed pragmatic positions - the first ( 1 ) is rather ironical, taking into account the unpredictable character of oil production; the other one (2) shows the tools of educated people.

Some more examples of conceptual metaphors:

dog catcher, syn.: dog chaser, eye rester - a very lazy worker;

widow maker - any device that could hurt or kill a worker;

rock hound, syn.: mud smeller, pebble picker, smeller, stone squirrel, wrinkle chaser -a rather long synonymic row to demonstrate the similarity of oil detecting to the process of hunting of different wild animals.

diplomatic overhead - The metaphor has two meanings, both negative - bribing and contraband oil. The general idea is of something illegal.

The function of Sublimate Evaluation is to serve as a kind of measure of the correspondence of the content of the analyzed words and phrases to the ideas of morality and aesthetics (aesthetic evaluation) that have been approved in society. Those assessments are the least common in the studied terminology, and among them one can distinguish aesthetic and moral assessments. The example of the moral assessment are the metaphors implying some divergence of the tools.

bastard box - a non-standard pipe collar;

bastard thread - a non-standard pipe thread.

Examples of aesthetic evaluation of metaphorical terms are:

rainbow - colours on a slush pit;

rainbow gold - oil, black gold.

Being of relatively abstract nature these assessments convincingly feature high expressiveness. The metaphorical term Rainbow (colours on a slush pit) in the oil-and-gas industry corresponds to the concept of "natural phenomenon of seven colours". When forming the term rainbow the quality of polychromy was selected in order to emphasize the 
surface on a slush pit. It can also be referred to a metaphor rainbow gold implying not only aesthetic evaluation, but financial value too.

\subsection{The source domains of oil-and-gas terminology metaphors}

The main cognitive source domains of metaphorical terms of the oil-and-gas field are: The world of human beings, the world of animals, the world of spatial orientation, the world of plants and insects, the world of sea, the world of natural and physical phenomena, the world of colours and shades, the world of weapons, the world of medicine, Food and Utensils. They are difficult to separate at times as the items are interwoven.

1. "The world of human beings" source domains includes metaphorical units that nominate human household items, clothing, food, physical, psychological and social forms of human life. For example:

bare headed \& tennis shoes - a deal of making a well with a postponed payment of wages in arrears;

back-to-back deal -a deal with mirror conditions;

bail throat-inner arc part of the swivel earring;

bow-tie effect-an effect looking like a gentleman's tie.

2. To the source domain "The world of animals" we have assigned words and phrases containing a name of a living creature in the animal kingdom. The metaphors depict similar functional or outward signs.

For example, the cluster fish convincingly shows how productive the metaphorical models based on the source domain "world of animals" are. They may be formed bearing in mind functional similarity (to fish, fisherman, fishing magnet, fishing tap) or shape conformity (fish eye, fishbone well, fishing jar, fishing neck, fish nail bit).

Other examples can be formed by association with bull, alligator, cat and some others:

bull scout, syn.: czar - a chairman of oil finders;

bull tongs, syn.: chain tongs - heavy tongs;

alligator wrench, bulldog wrench - sliding pipe wrench;

monkey board-runaround;

cathead-automatic spool reel;

rabbit-automatic pipe scraper.

3. The source domain of "The world of spatial orientation" consists of units that feature objects and subjects in terms of space, as well as in relation to each other.

A number of metaphors are formed by means of a highly productive prefix under-.

E.g.: underbalance,underbalanced drilling, underbalanced perforating, underground blowout, underlift, to underream, underreamer, underreaming.

The opposite position is nominated by roof and rock meaning an upper location:

E.g.: Roof, roof collapse, roof rock.

The low position express bottom metaphors:

E.g.: to bottom, bottom hole choke, bottom nose, bottom plug, to bottom out, syn.: to bottom, bottom water.

Also:

apples - objects falling from above (association with Newtonian apple),

top of fish-the upper part of a well.

4. To the source domain "The world of plants and insects" we attributed words and phrases containing the name of a plant or an insect

Butterfly valve - association is based on the similarity of a shape.

Grease orchard - oil field, i.e., a kind of a fruitful place.

5. To the source domain "The world of sea" belong objects and phenomena containing elements that are directly related to the marine theme. 
E. g. Atlantic Ocean-a well that gives salt water;

whale pastures - development of an offshore oil field from platforms.

6. To the source domain "The world of natural and physical phenomena" belong a few words and phrases that have language elements directly related to natural phenomena:

to moonlight - to perform illegal work on torpedoing wells at night, to conduct any activity at night.

7. To the source domain "The world of colours and shades" we refer words and phrases that have indicators of different colours and their combinations.

The most recurrent colours are green, black, blue.

E.g.: green bit, green cement, green field, green gas, green hand, green labor, green pattern.

All the green metaphors imply the quality of something not mature or formed.

The black metaphors are mostly associated with heavy or rude substances:

Black Magic - boring mud;

black oil - heavy petroleum residues;

blackjack, syn.: blackstrap-grease oil.

The blue chip sea metaphor is based on a secondary nomination of the well-known metaphor: blue chips are first-class securities in general economics, but in combination with the noun sea nominates the Gulf of Mexico as one of the richest in oil in the world.

The metaphor blue sky exploratory well depicts the unpredictable character of oil search and is based on the primary metaphor blue sky meaning something venturesome.

The metaphor blue whistler (natural gas well) refers to the colour of the gas and also to the sound of the hissing gas,

8. To the source domain "The world of weapons" belong words and phrases that contain language elements related to weapons.

shot density - the depth of gun perforation;

shot-in-the-dark - a random shot (while making a new well), syn. wildcat;

shotpoint - a place of a distant shot firing;

pressure bomb-deep pressure gauge.

9. To the source domain "The world of medicine" belong words and phrases containing language elements that are directly related to medicine or physiology:

passionate physician treatment - a process of hot refining;

Headache - look out!

brain, syn: brainstorm - an engineer;

brain bucket - a protective helmet;

bleed hole-tap hole;

to blind the line - spade off;

to cough itself into stable production - to clean the well;

dead-non-productive;

doctor solution -alkaline solution for the detection of sulfur compounds in petroleum products.

10. The source domain "Food and Utensils" includes the following metaphors:

biscuit cutter - drilling bit;

biscuits-core plug;

spaghetti string=macaroni string - a long and narrow string;

pepper - acid studge;

corkscrew hole - a well with a spiral hole.

They are but a few source domains of rethinking in the oil-and-gas sector terminology which is extremely rich in metaphors. The further study of it seems very promising. 


\section{Conclusion}

Summing up, we note the following.

The concepts that are fundamental and have the greatest practical significance for this industry are more often sublimated to metaphorical nomination.

The predominant type of axiological assessments is a cognitive evaluation.

The dominance of the source domain "the world of human beings" is only quite natural, anthropocentrism being inherent in the human mentality and reflecting a fundamentally important feature of metaphorical term formation particularly when nomination is previously unknown and accordingly devoid of linguistic expression of phenomena, processes, objects, subjects and their relationships. Also very productive are the animalistic domain, with lots of recurrent units, and the coloristic domain. The least productive domains are "The world of plants and insects" and "The world of natural and physical phenomena" (see Fig.1).

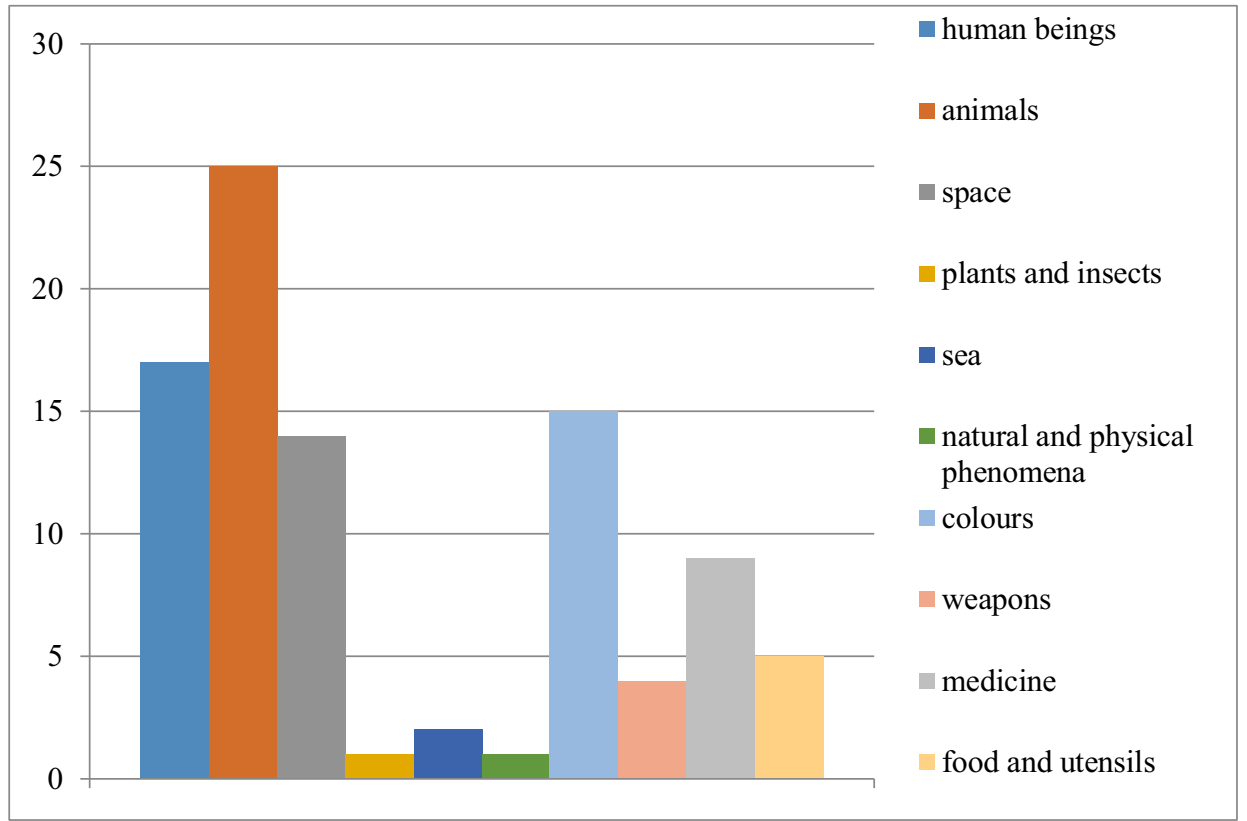

Fig. 1. Source Domains. Author's development.

The sampling of lexical units from the source domain is carried out not haphazardly but in the course of a scrupulous selection of possible potential words due to the attachment of their specific features and subsequent axiological evaluation.

\section{References}

1. A. Goatly, Language in Use, 157-167 (2020) doi:10.4324/9781003060994-15

2. R.W. Gibbs, Discourse Processes 48(8), 529-562 doi:10.1080/0163853X.2011.606103

3. M. Turner, Encyclopedia of Evolutionary Psychological Science, 1-3 (2016) doi:10.1007/978-3-319-16999-6_3328-1

4. G. Fauconnier, M. Turner, Polysemy and conceptual blending, Polysemy, 79-94 (2011) doi:10.1515/9783110895698.79 
5. G. Steen, Review of Cognitive Linguistics 9(1), 26-64 (2011) doi:10.1075/rcl.9.1.03ste

6. Z. Kövecses, Review of Cognitive Linguistics 18(1), 112-130 (2020) doi:10.1075/rcl.00053.kov

7. R. Trim, Metaphor and the Historical Evolution of Conceptual Mapping (Palgrave Macmillan, New York, NY, 2011)

8. Fan, Procedia Computer Science 131, 925-928 (2018) doi.org/10.1016/j.procs.2018.04.224

9. M. Benedek, R. Beaty, E. Jauk et al., NeuroImage 90, 99-106 (2014) doi.org/10.1016/j.neuroimage.2013.12.046

10. R. Bottini, Ch.F. Doeller, Trends in Cognitive Sciences 24, 606-619 (2020) doi.org/10.1016/j.tics.2020.05.008

11. M. Prandi, Metaphor and Symbol 27(2), 148-170 (2012) doi:10.1080/10926488.2012.667690

12. G. Lakoff, M. Johnson, Metaphors We Live By (University of Chicago Press, Chicago, 2008)

13. V.F. Novodranova, Cognitive Studies of Language 9, 136-139 (2011)

14. R.W. Gibbs, Journal of Pragmatics 90, 73-76 doi:10.1016/j.pragma.2015.03.016

15. G. Steen, Cognitive Semiotics 5, 179-197 (2013) doi:10.1515/cogsem.2013.5.12.179

16. L. Wee, Discourse Studies 7(3), 63-384 (2005) doi:10.1177/1461445605052191

17. T.B. Mikheeva, E.V. Murugova, SHS Web of Conf (2019) doi.org/10.1051/shsconf/20197007003

18. S.V. Pervukhina, O.A. Evtouchenko, L.Iu. Kotliarenko, M.P. Churikov, SHS Web of Conferences. Curr. Iss. Mod. Ling. Hum., 232-244 (2020) doi: $10.1051 /$ shsconf $/ 20208801013$

19. E.V. Murugova, EpSBS, 416-425 (2018) doi:10.15405/epsbs.2018.04.02.59

20. S. Pervukhina, V. Demchenko E3S Web of Conf. (ITSE 2020) 18033 (2020) doi:10.1051/e3sconf/202021018033

21. M. Zobel, H. Chatterjee, G. Matveeva, U. Kolb, R.B. Neder, Jour. Nanoparticle Res., 1-5 (2015) doi:10.1007/s11051-015-3006-5 